\title{
Ética, política e direito brasileiro: reflexões para um novo senso comum
}

Ethics, politics and the Brazilian law: reflections for a new common sense

\author{
Adriano Monteiro Madruga*
}

\begin{abstract}
Resumo:
O objetivo deste artigo é questionar o sentido enfático dado à ética no cenário político brasileiro na atualidade e seus reflexos no direito, já que historicamente a política e o direito estiveram sempre centralizados aos interesses dos grandes personagens e fatos (Hegel) e para contrapor essa percepção é pensada a história do Brasil como tragédia repetida por farsa (Marx) e o sentido de Pasárgada (Santos). A partir disso, re-pensar a ética como diálogo político (Platão) e a universalidade das leis (Cícero) no direito brasileiro na hodiernidade voltadas para cidadania através de movimentos de vanguarda refletidos por novos espelhos sociais para um novo senso comum (Santos).
\end{abstract}

Palavras-chave: Ética; Política; Direito Brasileiro.

\begin{abstract}
:
This article questioning the meaning given to emphatic ethics in Brazilian political scenario at present and its effect on the right, since historically politics and law have always been central to the interests of major characters and events (Hegel) and to counter this perception is thought the history of Brazil as a tragedy repeated farce (Marx) and direction of Pasárgada (Santos). From there, re -think the ethics and political dialogue (Plato) and the universality of laws (Cicero) in Brazilian law in modern towards citizenship through avant-garde movements reflected by new mirrors for a new social common sense (Santos).
\end{abstract}

Key words: Ethics; Politics; Brazilian Law.

\section{Introdução}

O presente artigo tem por objetivo compreender o sentido enigmático dado à ética que se enfatiza muito no cenário político brasileiro na atualidade e seus reflexos no direito, lócus que deveria garantir a valorização do sujeito através da cidadania e da

\footnotetext{
* Licenciado em História pela Universidade de Caxias do Sul (UCS); Graduando em Direito pela Universidade de Caxias do Sul; Professor de Ensino Médio do Estado do Rio Grande do Sul; E -mail: ammadrug@ucs.br
} 
justiça social no país. Esse desafio proposto segue num interesse de raposa ${ }^{1}$ "por várias coisas, [...] vários fins e objetivos - por vezes não-relacionados ou até mesmo contraditórios - cuja interconexão não é nem óbvia nem explícita." (LAFER, 2006, p. 13). A partir disso, se re-pensar em um novo senso comum que propicie movimentos de vanguarda refletidos em novos espelhos sociais através de "políticas públicas de segurança pautadas numa nova política judiciária" (SANTOS, 1999, p. 177) de acesso à cidadania a todos os sujeitos no país, e que o Es tado brasileiro de direito de fato cumpra com suas responsabilidades sociais com os seus cidadãos. Para isso, deve se pensar como "as raposas, que dessa maneira exprimem uma perspectiva centrífuga e pluralista da realidade" (LAFER, 2006, p. 13), de descentralização de verdades absolutas que silenciam as diferenças em nome da ordem e progresso, uma ordem que na verdade beneficia o progresso de poucos no Brasil: desde a Colônia, passando pela Proclamação da República até a hodiernidade.

\section{Ética como diálogo e universalidade das leis no sistema político -jurídico}

\section{brasileiro}

O discurso enfatizado pelos políticos na sociedade brasileira hodierna está pautado na palavra ética, cuja origem é o termo grego ethos. Como lembra Leonardo Boff (2003, p. 33) [grifo do autor], ethos " "não é primeiramente ética, mas a morada humana." A interpretação de ethos refletida por Boff, é pensada como ética do cuidado, e destacado o sentido de solidariedade traduzida nesse artigo como compreensão das experiências históricas na política e no direito e seus reflexos na sociedade brasileira atual. Já que historicamente a solidariedade foi muitas vezes silenciada em nome da ordem dos grandes personagens e fatos que lhe interessaram. E, a partir dessas experiências que muitas vezes foram silenciadas, como a Pedagogia da Libertação, re -pensar a ética

\footnotetext{
${ }^{1}$ Lafer (2006), nos seus estudos sobre o pensamento de Hannah Arendt, segue à classificação proposta pelo filósofo e historiador Isaiah Berlin para diferenciar pensador es de perspectiva centrípeta e monista, dos pensadores de perspectiva centrífuga e pluralista, divisão inspirada do seu verso favorito, do poeta grego Arquíloco: "Muitas coisas sabe a raposa; mas o ouriço uma grande."

2 Boff (2003, p. 32), reconstitui ethos/ morada humana na perspectiva filosófica grega para contrapor "a cultura dominante [...], materialista, individualista, consumista competitiva, prejudicando o capital social dos povos e precarizando as razões de estarmos juntos". Ethos/ morada humana é traduzida e refletida como solidariedade para re-pensar a política e o direito brasileiro, para um novo senso comum emancipatório.
} 
"estruturada ao redor dos valores fundamentais ligados à vida, ao seu cuidado, ao trabalho, às relações cooperativas e à cultura da não -violência e da paz. É um ethos que ama, cuida, se responsabiliza, se solidariza e se compadece" (BOFF, 2003, p.32). E, refletindo-se sobre a ética em uma perspectiva coletiva de valores sociais que constituem a identidade moral de uma nação (Brasil), percebe -se que esses valores não podem deixar de estar ligados à justiça (Estado de Direito) através de leis de acesso a todos os sujeitos, garantidos pela cidadania.

O direito não é uma simples idéia, é uma força viva. Por isso a justiça sustenta numa das mãos a balança com que pesa o direito, enquanto na outra segura a espada por meio da qual o defende. A espada sem a balança é a força bruta, a balança sem a espada, a impotência do direito. Uma completa a outra, e o verdadeiro estado de direito só pode existir quando a justiça sabe brandir a espada com a mesma habilidade com que manipula a balança (IHERING, 2007 , p. 27).

Após essa definição do sentido primeiro da ética e do equilíbrio que deve existir na espada e na balança no direito, analisa -se a perda desses sentidos por um viés obscuro de ausência de ética. Para se entender melhor essa reflexão, há uma necessidade de retornar aos gregos e romanos, mais precisamente a Platão (1980) e Cícero (2004), que acreditavam na superação dessa ausência de ética somente através do diálogo (princípio grego) e da universalidade das leis (princípio romano). Teoricamente para se chegar a u $\mathrm{m}$ amálgama desses princípios, no Brasil atual, é preciso mudar o sentido semântico político jurídico de políticas de segurança pública, para políticas públicas de segurança ${ }^{3}$. Porque, historicamente no Brasil houve sempre uma preocupação de manter a ordem dos grandes personagens por meios de leis criadas e garantidas através das políticas de segurança pública. Por exemplo, na Conjuração dos Alfaiates ocorrida na Bahia em 1789, o governo português para punir e intimidar a população da cidade de Salvador, executou quatros líderes rebeldes: detalhe, todos pobres e de origem negra, ou seja, sujeitos ausentes de cidadania. Já os líderes revoltosos de posição importante na sociedade de Salvador foram poupados, como o médico Cipriano Barata. Percebe -se que mesmo em situações dessa natureza a coerção mais severa das leis é aplicada aos sujeitos menos

\footnotetext{
${ }^{3}$ Essa inversão de Políticas de Segurança Pública para Políticas Públicas de Segurança é inspirada nas pesquisas realizadas pelo Núcleo de Estudos da Violência da USP.
} 
desprovidos de direitos garantidos pela cidadania. Na atualidade a história continua a se repetir como farsa presente no discurso da maioria dos políticos pautados nas políticas de segurança pública, de medidas paliativas de investimentos no setor de segurança: criação de mais presídios para diminuir a superlotação carcerária, aumento do conti ngente policial só para ficar nesses dois exemplos. Mas fica apenas na falácia dos políticos porque na realidade esses projetos ficam apenas na teoria e os presídios estão cada vez mais superlotados, depósitos dos herdeiros dos quatro líderes rebeldes pobr es executados pela Conjuração dos Alfaiates. E o policiamento é mal remunerado e facilmente corrompido pelo crime organizado/ poder paralelo ao Estado. A idéia proposta de mudança do sentido semântico político-jurídico de políticas de segurança pública, pa ra políticas públicas de segurança, é de oposição a essa mentalidade histórica que não tem mais sustentabilidade na sociedade brasileira hodierna.

Então, pensar em políticas públicas de segurança, é buscar igualdade entre os sujeitos através de direitos iguais garantidos pela cidadania na sociedade brasileira. Principalmente de oposição a essa mentalidade histórica viciosa de medidas paliativas que em muitos momentos históricos houve um radicalismo coercivo para manter a ordem estabelecida dos grandes perso nagens. Nesses momentos houve punições severas contra os sujeitos ausentes de cidadania, ou seja, verdadeiros massacres para restituir a ordem. Como exemplo disso tem-se os casos de Canudos no final do século xix e o massacre do Carandiru no final do sécul o xx. Então, os governantes (políticos) ao invés de continuarem reproduzindo esse discurso histórico falho de medidas paliativas que não se sustentam mais deveriam começar a pensar e a elaborar projetos de governo pautados em políticas públicas de segurança, de caráter preventivo frente as desigualdades sociais do país que resultam no aumento da criminalidade e da violência na sociedade brasileira.

Já que no discurso político atual enfatiza -se a ética, ela deveria ser pensada como responsabilidade social de "valores fundamentais ligados à vida, ao seu cuidado, ao trabalho, às relações cooperativas e à cultura da não -violência e da pa" (BOFF, 2003, p. 32). A ética pensada de maneira homogênea e não heterogênea. Com esse entendimento de ética e políticas públicas de segurança os governantes (políticos) ao invés de criarem projetos de construções de mais penitenciárias (teoria) que custam milhões aos cofres públicos para deslotar as existentes poderiam investir mais, por exemplo, numa educação 
pública de qualidade que forme cidadãos conscientes de seus direitos e deveres, fazendo com que as escolas públicas não sejam apenas depósito de crianças e adolescentes, que não vêm muito atrativo na sua forma de ensino defasado. O problema é mais visível nas zonas mais periféricas das grandes cidades em que as crianças e adolescentes pobres, padecendo de um determinismo social têm pouca perspectiva de vida no sentido de qualidade de vida e ascensão social. Muitas delas são cooptadas pelo crime organizado/ poder paralelo, já que vivem e convivem entre o poder legal do Estado com suas políticas sociais falhas (educação, saúde, habitação, direito, etc), mais voltadas para políticas de segurança e o poder paralelo do crime organizado que faz o papel "assistencial" nessas comunidades onde o Estado falhou. Mas, esse assistencialismo tem um preço cobrado pela lei do silêncio, da cooperação forçada e do medo.

Outra alternativa de políticas públicas de segurança (preventiva) entre tantas seria a de democratização do direito. A partir de então, chegar-se-ia a uma nova política judiciária, que, conforme a definição do sociólogo Boaventura de Sousa Santos (1999 , p. 177), "estaria comprometida com o processo de democratização do direito e da sociedade." Todavia, não adianta polemizar a tentativa de criação de leis que não irão solucionar os problemas criminais da sociedade brasileira gerados pela desigualdade social do país, como, por exemplo, a redução da maioridade penal de coerção em vão de combate à violência (barbárie). Se não existi r um diálogo e uma universalidade das leis de acesso a todos os cidadãos, que valorize o sujeito. Então, para que servirá a cidadania?

\section{A cidadania como ressurreição dos sujeitos da Pasárgada ${ }^{4}$ brasileira}

Se pensar em cidadania num país em que historicamente a cidadania foi pensada para poucos não é fácil, é como pensar nos doze trabalhos de Hércules, mas sem ser filho dos deuses. Portanto, para se entender o papel da cidadania como ressurreição dos sujeitos ausentes de cidadania na Pasárgada brasileira contemporânea, é necessário compreender a reflexão de Cícero (2004, p. 53):

\footnotetext{
${ }^{4}$ Sujeitos ausentes de cidadania e que formam um direito paralelo ao oficial.
} 
[a cidadania só tem legitimidade] se os homens conformassem seus juízos à Natureza ${ }^{5}$ e ao pensamento do poeta - 'nada do que é humano nos é estranho' $^{6}$ - todos respeitariam por igual o Direito. Todos receberam da Natureza a razão, e por ela a Lei, que outra coisa não é que a reta razão, quando ordena e quando proíbe. $E$, se receberam a Lei, também receberam o Direito. Pois bem, como a razão foi dada a todos, conclui -se que todos receberam o Direito. Por isso, Sócrates tinha bons motivos para amaldiçoar o primeiro homem que separou a utilidade e o Direito, e lamentar o que se tornou, segundo ele, o princípio de todas as desgraças ${ }^{7}$ [grifo do autor].

Essa passagem de Cícero esclarece o papel fundamental da cidadania para o sujeito, porém, deixa uma ressalva na voz de Sócrates, da ruptura causada entre utilidade (razão + Lei = reta razão) e o Direito. E, se pensando em nível de Brasil, como identificar historicamente "todas as desgraças" dos sujeitos ausentes de cidadania? Para responder essa indagação precisei estabelecer um diálogo com o Divino ${ }^{8}$, que expressou em um dos seus diálogos "que não são legítimas as leis e as formas de governo que não forem estabelecidas com vista no interesse da comunidade. As que forem feitas para vantagem de uns poucos - não direi cidadãos, porém sectários - dar-Ihes o qualificativo de justo é abusar da expressão" (PLATÃO, 1980, p. 126). A resposta do Divino é divina pois revela as origens dessas desgraças, originadas pelas seitas (sectários) ${ }^{9}$ dos grandes personagens ${ }^{10}$ em detrimento dos sujeitos ausentes de cidadania que formam a Pasárgada Brasileira. Porque

os grupos dominantes, historicamente, produziram o inusitado: a 'estigmatização do espaço' apropriado pelas classes trabalhadoras. Em outras palavras, o favelado é considerado classe perigosa atualmente por representar

${ }^{5} \mathrm{O}$ tradutor da obra (2004) de Cícero do latim para o português, o professor universitário (UCS) e jurista Marino Kury (2004, p. 21) [grifo do aut or], em nota introdutória da respectiva obra estabelece o sentido dado por Cícero ao "conceito de Lei Natural, acima das legislações particulares, inerente à natureza moral do homem e em harmonia com a estrutura racional do universo, firmadas em princípios éticojurídicos imutáveis; Lei digna de tal nome, feita para o bem dos cidadãos e dos Estados, objetivando a segurança, a tranqüilidade e a felicidade dos homens."

${ }^{6}$ Kury (2004, p. 53) [grifo do autor], nota de rodapé: "Essa frase famosa é atribuída ao cômico Terêncio, imitador do grego Menandro."

${ }^{7}$ Kury (2004, p. 53) [grifo do autor], nota de rodapé: Segundo Clemente de Alexandria (Stromata, II, 21, 3), o estóico Cleantes atribuiu essa opinião a Sócrates. Na realidade, tais idéias conformam -se com o pensamento do Sócrates platônico.

${ }^{8}$ Cícero grande admirador de Platão, a quem chamava de divino, e que dedicou dois títulos dos seus livros: A República e o Tratado das Leis, escritos em forma de diálogo a maneira do mestre.

${ }^{9}$ As oligarquias fundiárias, a aristocracia industrial, as corporações transnacionais.

${ }^{10}$ Grandes fatos personagens usados para descrever e diferenciar os privilegiados e detentores do poder na política e no direito brasileiro, exemplo feriados nacionais: Proclamação da Independência que trocou uma monarquia por outra, Proclamação da República que substituiu uma elite monarquista por uma republicana nos moldes do pensamento positivista e das oligarquias regionais. 
o diferente, o Outro, no que se refere à ocupação do espaço urbano. [...] são classificados, em geral, pelos formadores de opinião, como pertencentes às 'classes perigosas' (CAMPOS, 2005, p. 63).

A partir dessas reflexões filosóficas, históricas e sociológicas no campo da política e do direito brasileiro, se compreende melhor a ausência de ética na sociedade brasileira atualmente e seus reflexos na cidadania. E quem melhor definiu essa ausência de ética foi Guimarães Rosa, na sua famosa declaração: "O político pensa apenas em minutos. Sou escritor e penso em eternidades. Eu penso na ressurreição do homem" (ROSA apud ALVES, 2002, p. 11). Com essa declaração se percebe que esses minutos simbolicamente se traduzem como ausência de ética para os sujeitos excluídos de cidadania da Pasárgada brasileira, em benefício da cidadania dos grandes personagens privilegiados historicamente pela política e pelo direito brasileiro através das políticas de segurança pública. Isso remonta a chegada portuguesa com o degredo (excluídos do Reino Português para a Colônia), as escravidões indígena e afri cana, a Independência do Brasil (1822) e da República (1889), as ditaduras (Era Vargas - Estado Novo 1937-1945, Ditadura Militar 1964-1985), que deixaram como herança aos sujeitos ausentes de cidadania uma identidade do sempre, ou seja, sempre dissidentes e deportados (degredo), sempre explorados e coagidos (escravidão), sempre excluídos da política e do direito (Independência), sempre reprimidos nos movimentos sociais de vanguarda (ditadura), criando-se para a Pasárgada brasileira uma cultura baseada na id entidade do medo, da mentira, das medidas paliativas. Um medo garantido por um poder simbólico (BOURDIEU, 2001), perpetuado pelos "formadores de opinião, [que julgam os sujeitos ausentes de cidadania,] como pertencentes às 'classes perigosa."' (CAMPOS, 2005, p. 63). Historicamente, os quilombolas por terem representado, no passado, ameaça ao Império; e os favelados por se constituírem em elementos socialmente indesejáveis após a instalação da República (CAMPOS, 2005, p 64). Uma tragédia do medo repetida por farsa da mentira: Lei Áurea, libertou os escravos das senzalas para serem engolidos pelas ovelhas dos enclosures dos grandes personagens em terra tupiniquim (MORE, 2001). Farsa essa garantida pelas medidas paliativas das políticas de segurança pública que cercam os grandes latifúndios rurais, garantem a especulação imobiliária nos grandes centros urbanos industrializados (Caxias do Sul, São Paulo), e coagindo movimentos 
sociais gerados pela ausência de ética, como, por exemplo, dos sem -terra, dos sem-teto, dos sem-educação, dos sem-saúde, enfim, dos sem-cidadania.

Isso lembra um livro escrito em 1902, (CUNHA, 1938) e seus escritos continuam atualizados na sociedade brasileira. Retrata o choque de civilizações: a civilização dos especialistas da jovem República em oposição à civilização dos bárbaros dos sertões brasileiros afora e sua identidade do medo, da mentira e das medidas paliativas. Os bárbaros matutos não se enquadravam nos moldes políticos do novo país (continuam não se enquadrando), e conseqüentemente, não teriam direito a participarem da política e, por advertência, foram excluídos da cidadania da ordem e progresso por serem de raça inferior. Seus únicos direitos eram pagar tributos ao novo país do futuro, caso contrário, eram conspiradores da monarquia e suas diferenças deveriam ser silenciadas. Assim, a imensa favela construída no sertão pelos degredados

matutos broncos foram varridos cedo, - surprehendidos (sic), saltando estonteadamente das rêdes (sic) e dos catres miseraveis (si c), - porque havia pouco mais de cem annos (sic) um grupo de sonhadores falara nos direitos do homem e se batera pela utopia maravilhosa da fraternidade (CUNHA, 1938 , p. 448).

Onde foi parar a utopia da Pasárgada brasileira? Nas eternidades, nas ressurreições dos homens, iluminada na vanguarda dos jardineiros poetas que sonham com grandes jardins de cidadania.

\footnotetext{
Um político por vocação é um poeta forte: ele tem o poder de transf ormar poemas sobre jardins em jardins de verdade. A vocação política é transformar sonhos em realidade. É uma vocação tão feliz que Platão sugeriu que os políticos não precisam possuir nada: bastar -lhes-ia o grande jardim para todos. Seria indigno que o jardineiro tivesse um espaço privilegiado, melhor e diferente do espaço ocupado por todos (ALVES, 2002 , p. 10).
}

Esse, portanto, é o desafio da utopia vanguardista Brasil, sonhada por novos espelhos sociais, espelhos para a eternidade de um povo (Brasil), d e ressurreição do sujeito e respeito à cidadania. Porque "conheci e conheço muitos políticos por vocação. Sua vida foi e continua a ser um motivo de esperança" ( ALVES, 2002, p. 10) no diálogo e universalidade das leis norteadas por uma ética de jardineiro com sonhos de cidadania. 


\section{O Direito dos grandes personagens e a Pasárgada brasileira}

"Hegel observa em uma de suas obras que todos os fatos e personagens de grande importância na história do mundo ocorrem, p or assim dizer, duas vezes. E esqueceu -se de acrescentar: a primeira vez como tragédia, a segunda como fars" (MARX, 1997, p. 21). Essa reflexão de Marx vai contra ao pensamento hegeliano, revelando o ponto crucial onde a história é construída para o intere sse de poucos, no discurso simbólico dos grandes personagens que, através dos fatos que Ihe interessam, o regularizam em leis. $\mathrm{E}$ trazendo essa repetição dos grandes personagens e fatos a Pasárgada brasileira através do poema de Manuel Bandeira (2007, p. 147), se podem destacar os seguintes versos: "Vou-me embora pra Pasárgada"11 / Em Pasárgada tem tudo/ É outra civilização/ Tem um processo seguro/ De impedir a concepção." Esses versos refletem a falta de identidade e crença na política brasileira dos grandes personagens e fatos, que se consolida no descompasso da balança e da espada nas mãos do direito e leva à perda da ética como ethos de morada humana. Esse descompasso do direito e da falta de ética reflete em um poder paralelo dentro do Estado brasileiro atual; contexto estudado por Santos numa favela carioca ${ }^{12}$, denominada metaforicamente de Pasárgada. O estudo de Santos (2002) demonstrou a crise do sistema político-jurídico brasileiro, de hipertrofiação das leis em favor dos grandes personagens em detrimento aos sujeitos menos privilegiados pela cidadania do Estado de Direito Brasileiro.

Historicamente, para compreender os grandes personagens e fatos brasileiros em oposição aos sujeitos não-cidadãos (Pasárgada) que reflete na atualidade brasileira, basta pegar o caso do Quilombo dos Palmares, de Zumbi, símbolo dos sujeitos não -cidadãos que formaram um direito paralelo/ poder paralelo, ou seja, a Pasárgada; do governador de Pernambuco, Souto Maior, símbolo da aristocracia dos grandes personagens detentores do poder político oficial e o bandeirante Domingo Jorge Velho, símbolo do direito das políticas de segurança pública contra os menos favorecidos (sujeitos não cidadãos do Estado brasileiro). A tragédia da Pasárgada brasileira no período Colonial

\footnotetext{
${ }^{11}$ Capital do antigo Império da Pérsia de Ciro II. Significa campo dos persas ou tesouro dos persas.

12 Estudo de tese de doutoramento apresentado na Universidade de Yale (EUA), realizado na favela do Jacarezinho (Rio de Janeiro), no início da década de 70 do século XX. Nesse estudo do sociólogo Boaventura de Sousa Santos é analisado um direito paralelo entre esses moradores a o oficial do país. Que pode se dizer que é o reflexo na atualidade de facções criminais e divulgadas na impressa como poder paralelo.
} 
(Quilombo dos Palmares) se repete como farsa em Canudos e no Contestado, seus direitos paralelos foram silenciados pelas políticas de segurança pública, em nome da ordem e progresso dos especialistas e das oligarquias regionais (coronéis) no período da República Velha. Com esse exemplo do Quilombo dos Palmares, Canudos e Contestado, há uma compreensão melhor desses poderes paralelos que estão institucionalizados ou não-institucionalizados na atualidade brasileira, onde uma escória produz outra.

Hodiernamente a história continua a se repetir como farsa no Estado brasileiro fruto da corrupção política e ausência de ética, exemplo disso: a promessa de uma Reforma Agrária que não se faz por incompetência administrativa do Estado, fruto de interesses particulares dos grandes personagens. A partir disso, aumenta o êxodo rural fruto desses jogos de interesses, desenfreando a migração interna de explosão demográfica sem planejamento urbano nos grandes centros, e por fim, gerando caos social: favelas, desemprego em massa, presídios com super lotação etc; que conseqüentemente, produzem frutos tais como Pasárgad as institucionalizadas e nãoinstitucionalizadas com seus próprios direitos: Esquema PC, Anões do Orçamento, Mensalão, Comando Vermelho, Primeiro Comando da Capital e outras facções onde uma escória legal produz outra paralela. Isso é simplificado no afori smo de Cunha (1938, p. 218) [grifo do autor], "o jagunço, saqueador de cidades, succedeu (sic) ao garimpeiro, saqueador da terra. O mandão político substituiu o capangueiro decahido (sic)."

A partir disso, a pergunta que não pode calar remete a Rousseau (2001) com seu princípio de comunidade que leva à participação (cidadania) e à solidariedade (sujeito). Então, onde elas foram parar ao longo da História do Brasil? Será que Nietzsche (1999 , p 51) estava certo ao afirmar que o "Estado chama-se o mais frio de todos os monstros. Mente também friamente, e eis que mentira rasteira sai da sua boca: 'Eu, o Estado, sou o povo"'. A mentira do Estado brasileiro de direitos iguais a todos se justifica na própria bandeira nacional com slogan "ordem e progresso" idealizando um "poder simbólico é, com efeito, esse poder invisível o qual só pode ser exercido com a cumplicidade daqueles que não querem saber que lhe estão sujeitos ou mesmo que o exercem" (BOURDIEU, 2001, p. 7-8). Isso é legalizado através de leis criadas e aprovadas pelos representantes do povo que reprimem movimentos sociais, e conseqüentemente, garantem aos grandes 
personagens direitos herdados das Capitanias Hereditárias através das políticas de segurança pública na contemporaneidade do Estado brasileiro.

O próprio Rousseau (2001, p 83), admitiu que "nunca existiu verdadeira democracia, nem jamais existirá". Mas, segundo os gregos, que criaram o mito da Caixa de Pandora $^{13}$, caso houvesse crença na esperança nem um mal poderia acontecer por inteiro e aos sujeitos ausentes de cidadania da Pasárgada brasileira resta uma esperança nos movimentos de vanguarda como, por exemplo, as políticas públicas de segurança.

\begin{abstract}
Essa expressão sinaliza que as políticas de segurança devem estar articuladas às diferentes áreas de atuação do poder público: saúde, educação, e habitação, para ficar em apenas alguns exemplos. Portanto, nas democracias consolidadas, a segurança pública está sendo pensada cada vez mais numa dimensão multidisciplinar. Sem dúvida, essa abordagem condiz com a defesa integral dos Direitos Humanos. Mas, no Brasil, segurança social é uma idéia que está em seus primeiros passos (ALVAREZ; SALLA, 2006, p. 2) [grifo nosso].
\end{abstract}

Entretanto, resta a esperança em um novo senso comum através de movimentos de vanguarda refletidos em novos espelhos sociais conduzidos, por exemplo, nas políticas públicas de segurança e na utópica democracia participativa de ideal rousseauniana.

\title{
A utópica democracia participativa como novo espelho no mul ticulturalismo brasileiro
}

Para Montesquieu (2000, p. 19) [grifo do autor], "na república, o povo em conjunto possui o poder soberano, trata-se de uma Democracia. Quando o poder soberano está nas mãos de uma parte do povo, chama -se uma Aristocracia." Sobre a Democracia, seu princípio é a virtude moral: uma virtude de respeito às leis presentes na sociedade. E, refletindo o seu papel como regime oficial da Republica Federativa do Brasil, que garante aos sujeitos a cidadania e a igualdade perante a lei, basta pegar a Constituição Federal de 1988 (2001, p. 3), no seu artigo 5 que diz: “Todos são iguais perante a lei, sem distinção de qualquer natureza" Mas, quando se perde essa referência democrática como a expressa no artigo 5o da Constituição Federal por viés de um poder simbólico, o povo passa a se alienar e vai perdendo aos poucos os sentimentos que possuem como sujeitos donos de uma cidadania; e, conseqüentemente o poder soberano passa a ser conduzido

\footnotetext{
${ }^{13}$ Caixa de Pandora: da qual todos os males do mundo saíram, apenas ficando presa a esperança.
} 
nas mãos de poucos (Aristocracia). Entretanto, na definição de Montesquieu, essa falta de referência não pode conduzir a uma crítica da razão indolente ${ }^{14}$, pois, essa indolência leva ao medo, acarretando as perdas dos direitos políticos -sociais e do espírito solidário de comunidade do povo. Na definição de Santos (2005, p. 48):

Quando isso acontece, a sociedade entra numa crise que podemos designar como crise da consciência espetacular: de um lado, o olhar da sociedade à beira do terror de não ver reflectida (sic) nenhuma imagem que reconheça como sua; do outro lado, o olhar mo numental, tão fixo quanto opaco, do espelho tornado estátua que parece atrair o olhar da sociedade, não para que este veja, mas para que seja vigiado.

Então, esses espelhos, que foram transformados em estátuas precisam ser derrubados e substituídos por novos espelhos, para um novo senso comum, de redescoberta do ethos e para universalidade das leis, mas sempre respeitando o multiculturalismo (diferenças regionais dentro do Brasil) que se opõem ao silêncio e a diferença através do diálogo por meio da "teoria da tradução que sirva de suporte epistemológico às práticas emancipatórias, todas elas finitas e incompletas e, por isso, apenas sustentáveis quando ligadas em red" (SANTOS, 2005, p. 30) [grifo do autor]. Essas práticas emancipatórias, no caso Brasil, de comprometimento com a cidadania social, sempre foram silenciadas em vários momentos históricos do país em nome da ordem. Em Canudos, por exemplo, a diferença era silenciada pela

\begin{abstract}
degollação (sic) era, por isto, infinitamente mais pratica (sic), dizia -se nuamente. Aquillo (sic) não era uma campanha, era uma xarqueada (sic). Não era a acção (sic) severa das leis, era a vingança. Dente por dente. [...] devia-se queimar. [...] devia-se degollar. (sic) A repressão tinha dous (sic) polos (sic) - o incendio (sic) e a faca (CUNHA, 1938, p. 569).
\end{abstract}

Tragédia que se repetiu como farsa escrita da mesma forma, com os mesmos versos clássicos da literatura de repressão. Dessa vez, os inimigos não era $\mathrm{m}$ mais os bárbaros matutos monarquistas excluídos pela Lei Áurea e pela nova República dos especialistas detentores da ordem histórica para o progresso dos grandes personagens. Os versos repetidos eram em nome da Marcha da Família com Deus pela Liberdade, onde as

\footnotetext{
${ }^{14}$ A razão indolente que penso em Montesquieu (2000) é proposta na obra de Santos (2005), autor que se inspirou em Leibniz, no Prefácio do seu Ensaio de Teodicéia sobre a bondade de Deus, a liberdade do homem e a origem do mal, 1710.
} 
políticas de segurança pública foram adicionadas pela Ditadura Militar (1964-1985) que reprimiu movimentos sociais de novos espelhos como a Pedagogia da Libertação freiriana e que retirou dos currículos escolares disciplinas essências para uma soc iedade consciente de sua cidadania: Latim, Grego, Filosofia e Sociologia. Toda essa violência contra os menos desprovidos de direitos e cidadania sempre foi justificada em nome da diferença e ordem histórica dos grandes personagens conduzidos pelos grandes fatos.

É como se o espelho passasse de objecto (sic) trivial a enigmático super -sujeito, de espelho passasse a estátua. Perante a estátua, a sociedade pode, quando muito, imaginar-se como foi ou, pelo contrário, como nunca foi. Deixa, no entanto, de ver nela uma imagem credível do que imagina ser quando olha. A actualidade (sic) do olhar deix a de corresponder à actualidade (sic) da imagem (SANTOS, 2005, p. 48).

Mas, os novos espelhos sociais a serem pensados e construídos por um "novo senso comum" devem ter como reflexo uma democracia participativa, de ética solidár ia no respeito às diferenças regionais traduzidas por diálogo e universalidade das leis compreendidas por todos os sujeitos e ligadas em rede para construção do direito brasileiro de valorização da cidadania social. Essa cidadania pensada pelo povo brasile iro para o povo brasileiro, através de uma dimensão multidisciplinar comprometida com 0 processo de democratização do direito e da sociedade (SANTOS, 1999, p. 177); e não mais pensada por uma aristocracia para uma aristodemocracia mascarada pelos grandes personagens e fatos que lhe interessam e que usam a democracia e o direito, por meio da corrupção e da falta de ética social de uma parcela de políticos que servem aos seus interesses particulares dentro do Estado brasileiro de direito democrático.

\section{Conclusão}

Vem-me à mente o verso da poe tisa Cecília Meireles (2003, p. 64), “Em que espelho ficou perdida a minha face?" Esse é o desafio da busca de novos espelhos sociais na ética tão falada, mas pouco entendida pelos políticos na sociedade brasileira hodierna que reflete no direito. Então, a ética que historicamente na política e no direito brasileiro sempre foram como o verso acima para os sujeitos não-cidadãos ao longo da história da Pasárgada Brasileira, deve seguir por novos espelhos sociais de movimentos de vanguarda para "transformar-se num novo senso comum, um senso comum emancipatório. Não há 
vanguardas senão na cabeça dos vanguardistas" (SANTOS, 2005, 'p. 17). Esse é o desafio proposto nesse artigo. E, ficando como reflexão as palavras de Ihering $(2007$, p. 27): "A vida do direito é a luta: luta dos povos, dos governos, das classes sociais, dos indivíduos."

\section{Referências}

ALVAREZ, M.C.; SALLA, F. Construção das políticas de segurança pública e o sentido da punição, São Paulo (1822-2000). In: ENCONTRO ESTADUAL DE HISTÓRIA, 8., 2006, Caxias do Sul. Anais. Anais... Caxias do Sul: ANPUHRS, 2006. p. 1-10.

ALVES, R. Conversas sobre política. 5.ed. Campinas: Versus, 2002.

BANDEIRA, M. Estrela da vida inteira. Rio de Janeiro: Nova Fronteira, 2007.

BOFF, L. Ética e moral: a busca dos fundamentos. 2.ed. Petrópolis: Vozes, 2003.

BOURDIEU, P.O poder simbólico. 4.ed. Rio de Janeiro: Bertrand, 2001.

BRASIL. Constituição Federal Interpretada pelo STF. 6.ed. São Paulo: Juarez de Oliveira, 2001.

CAMPOS, A. Do quilombo à favela: a produção do "espaço criminalizado" no rio de janeiro. Rio de Janeiro: Bertrand Brasil, 2005.

CÍCERO, M.T. Tratado das leis. Caxias do Sul: EDUCS, 2004.

CUNHA, E. Os sertões: campanha de canudos. 12.ed. Rio de Janeiro: Francisco Alves, 1933.

IHERING, R.V. A luta pelo direito. São Paulo: Martin Claret, 2007.

LAFER, C. A reconstrução dos direitos humanos: um diálogo com o pensamento de Hannah Arendt. São Paulo: Companhia das Letras, 2006.

MARX, K. O 18 brumário e cartas a Kugelmann . 6.ed. Rio de Janeiro: Paz e Terra, 1997.

MEIRELES, C. Flor de poemas. Rio de Janeiro: Nova Fronteira, 2003.

MONTESQUIEU. O espírito das leis. 2.ed. São Paulo: Martins Fontes, 2000.

MORE, T. A utopia. São Paulo: Martin Clarent, 2001.

NIETZSCHE, F.W. Assim falava Zaratustra: um livro para todos e para ninguém. São Paulo: Martin Claret, 1999.

PLATÃO. Diálogos: leis e epinomis: vol. XII-XIII. Belem: Universidade Federal do Pará, 1980. 
ROUSSEAU, J.J. O contrato social: princípios do direito político. 3.ed. São Paulo: Martins Fontes, 2001.

SANTOS, B.S. Pela mão de Alice: o social e o político na pó s-modernidade. 6.ed. São Paulo: Cortez, 1999.

. A crítica da razão indolente: contra o desperdício da experiência. 5.ed. São Paulo: Cortez, 2005.

Notas sobre a história jurídico-social de pasárgada. In: SOUTO, Cláudio; FALCÃO, Joaquim. Sociologia e direito: textos básicos para a disciplina de sociologia jurídica. 2.ed. São Paulo: Pioneira, 2002. p. 107-117. 